Faculdade

de Ciências Econômicas UFRGS
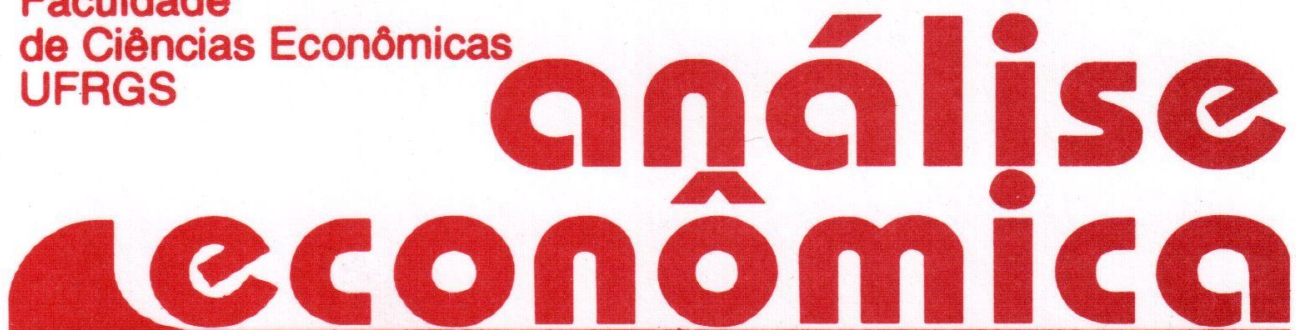

- SIDERURGIA E O PARADIGMA TECNOLÓGICO

Angela Maria Morandi

- ESTIMATING PRIVATE DEMANDS FOR PUBLIC GOODS

Eduardo Pontual Ribeiro

- KEYNES E A ATUALIDADE DA TEORIA KEYNESIANA

Fernando Ferrari Filho

- IMPRODUTIVIDADE DE UM CONCEITO DE PRODUÇÃO Raul Cristóvão dos Santos

- A NEGAÇÃo dA INEFICÁCIA DA POLÍTICA MONETÁRIA João Sicsú

- DESREgulamentAÇÃo, globa LIZAÇÃo E A CADEIA DO TRIGO Lena Lavinas

Manoel Magina

- ALUGUÉIS RESIDENCIAIS EM PORTO ALEGRE

Marco Aurélio Stumpf González

- POLICY INTERVENTION AND THE TRADE-OFF BETWEEN GROWTH AND DISTRIBUTION OF INCOME Joanílio Rodolpho Teixeira Jorge Thompson Araujo

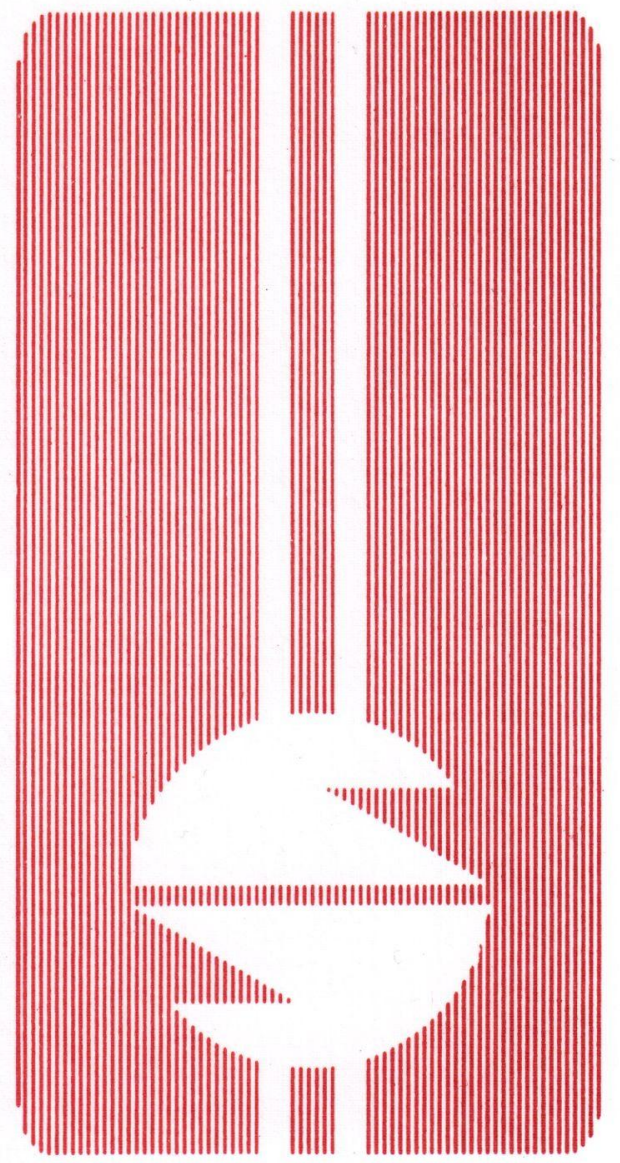


UNIVERSIDADE FEDERAL DO RIO GRANDE DO SUL

Reitora: Prof ${ }^{a}$. Wrana Maria Panizzi

FACULDADE DE CIENNCIAS ECONÓMICAS

Diretora: Prof ${ }^{\mathrm{a}}$. Otilia Beatriz Kroeff Carrion

CENTRO DE ESTUDOS E PEQUISAS ECONÔMICAS

Diretor. Prof. Fernando Ferrari Filho

DEPARTAMENTO DE CIÊNCIAS ECONÓMICAS

Chefe: Prof. Gentil Corazza

CURSO DE PÓS-GRADUAÇÃO EM ECONOMIA

Coordenador. Prof. Marcelo Savino Portugal

CURSO DE PÓS-GRADUAÇÃO EM ECONOMIA RURAL

Coordenador: Prof. Carlos Guilherme A. Mielitz Netto

CONSELHO EDITORIAL: Achyles B. Costa, Aray M. Feldens, Carlos A. Crusius, Carlos G. A. Mielitz Netto, Eduardo A. Maldonado Filho, Eduardo P. Ribeiro, Eugênio Lagemann, Fernando Ferrari Filho, Gentil Corazza, Marcelo S. Portugal, Nali J. Souza, Otília B. K. Carrion, Paulo A. Spohr, Paulo D. Waquil, Pedro C. D. Fonseca, Roberto C. Moraes, Ronald Otto Hillbrecht, Stefano Florissi, Eleutério F. S. Prado (USP), Fernando H. Barbosa (FGV/RJ), Gustavo Franco (PUC/RJ), João R. Sanson (UFSC), Joaquim P. Andrade (UnB), Juan H. Moldau (USP), Paul Davidson (Univ. of Tennessee), Werner Baer (Univ. of Illinois).

COMISSÃO EDITORIAL: Eduardo Augusto Maldonado Filho, Fernando Ferrari Filho, Gentil Corazza, Paulo Dabdab Waquil, Marcelo Savino Portugal, Roberto Camps Moraes.

EDITOR: Nali de Jesus de Souza

SECRETARIA: Cláudia Porto Silveira, Sandra Mascarello e Fábio Régis Sparremberger. Revisão de textos: Vanete Ricacheski.

FUNDADOR: Prof. Antônio Carlos Santos Rosa

Os materiais publicados na revista Análise Económica são da exclusiva responsabilidade dos autores. É permitida a reprodução total ou parcial dos trabalhos, desde que seja citada a fonte. Aceita-se permuta com revistas congêneres. Aceitam-se, também, livros para divulgação, elaboração de resenhas e recensões. Toda correspondência, material para publicação (vide normas na terceira capa), assinaturas e permutas devem ser dirigidos ao seguinte destinatário:

PROF. NALI DE JESUS DE SOUZA

Revista Análise Econômica - Av. João Pessoa, 52

CEP 90040-000 PORTO ALEGRE - RS, BRASIL

Telefones: (051) 316-3348 e 316-3440 - Fax: (051) 316-3990

nali@vortex.ufrgs.br 


\title{
VARIAÇÃO QUALITATIVA E ÍNDICES DE PREÇOS NA ANÁLISE DO COMPORTAMENTO RECENTE DOS ALUGUÉIS RESIDENCIAIS EM PORTO ALEGRE (1994-1997)
}

\author{
Marco Aurélio Stumpf González
}

\begin{abstract}
SINOPSE
O segmento de locações residenciais do mercado imobiliário é muito sensível às transformaçōes macroeconômicas e legais. No Brasil, o Plano Real é um exemplo recente de intervenção governamental na economia. Neste artigo, analisa-se os efeitos que o Plano Real provocou no mercado de locações de Porte Alegre, investigando-se as variaçōes de oferta e de preços de apartamentos. A análise baseia-se em dados coletados pelo sindicato das imobiliárias e em índices hedônicos de preços.
\end{abstract}

Cód. AEA: 630 Palavras-chave: aluguel; mercado imobiliário, modelos hedônicos

\section{ABSTRACT}

Rental market segment of real estate is very sensible to macroeconomic and law national situation. The Brazilian "Real Plan" is a recent example of government intervention on economy, and over real estate market. This paper investigates the influence of this stabilization plan on values and offer number of residential apartments to rent in Porto Alegre city, comparing the values before and after your edition by statistical data and hedonic models.

AEA Code: 630

Key Words: rent; real-estate market, hedonic models.

\footnotetext{
* Engenheiro Civil, Mestre em Engenharia e Doutorando em Economia na UFRGS Professor da Universidade do Vale do Rio dos Sinos.

E-Mail: Gonzalez@Labcad Unisinos.Tche.Br.
}

\begin{tabular}{|l|l|l|l|l|}
\hline ANÁLISE ECONÔMICA & ANO 15 & N. 28 & Setembro/97 & p. 133-147 \\
\hline
\end{tabular}




\section{INTRODUÇÃO}

O mercado imobiliário é responsável por uma significativa parte da economia nacional. As características peculiares dos bens transacionados 0 diferenciam de outros mercados, tais como heterogeneidade, durabilidade, imobilidade e custo elevado. A influência das condições macroeconômicas nacionais é ainda mais acentuada no setor de locações. O Governo Federal interfere no mercado de duas formas: modificando a legislação que regula os contratos e alterando as condições econômicas (Kempner e Fine, 1989; Lavender, 1990; Robinson, 1979; Wiktorin, 1992).

0 advento de um plano de estabilização econômica como o Plano Real, acompanhado de um conjunto de medidas complementares e de uma relativa tranqüilidade política e econômica, permite supor alterações no mercado imobiliário. Passados mais de dois anos da implantação deste plano, seus efeitos já podem ser investigados.

Este trabalho analisa os valores ofertados de aluguéis, desde antes do Real até abril de 1997, verificando as transformações que ocorreram. O estudo desenvolvido inicialmente apresenta uma análise sobre os dados das pesquisas mensais do Sindicato das imobiliárias que, embora contenham alguns problemas metodológicos, constituem-se no único dado estatístico disponível (González, 1993; Secovi, 1991-1997).

Em seguida, para identificação do comportamento dos aluguéis, foram também coletados dados de apartamentos residenciais em Porto Alegre, diretamente do mercado, formando uma amostra de tamanho considerável, analisada através de modelos de formação de preços.

\section{ANÁLISE DOS DADOS ESTATÍSTICOS}

Esta seção é baseada em dados publicados mensalmente pelo sindicato das empresas imobiliárias (Secovi/RS). Este organismo coleta informações diretamente dos classificados de jornais, utilizando uma edição dominical por mês. Não há conferência dos valores ou das características dos imóveis, nem da efetivação da transação. Os resultados são médias aritméticas simples, desconsiderando a heterogeneidade dos imóveis. Uma parcela dos anúncios consiste de imóveis anunciados repetidas vezes, mas a consideração de apenas uma semana no mês provoca a exclusão de cerca de $20 \%$ das ofertas, segundo os responsáveis pela pesquisa. A diferença consiste de imóveis anunciados apenas nas outras semanas, mercado informal e imobiliárias que não trabalham com anúncios em jornais. As pesquisas levam em conta os valores nominais dos aluguéis, não considerando os descontos ou bonificações que têm sido concedidos nos últimos meses (González, 1993; Secovi, 1991-1997). 
Contudo, os problemas apresentados não são empecilhos ao tipo de análise apresentada a seguir. Trata-se de série histórica coletada com o mesmo método, portanto com dados comparáveis, permitindo identificar as variações do mercado. Os descontos nos aluguéis atingem em geral apenas a primeira parcela, diluindo-se nos prazos normais para os contratos novos (30 meses). Além disto, em trabalhos anteriores, foi detectado que as imobiliárias de Porto Alegre anunciem cerca de $99 \%$ das ofertas no principal jornal da cidade (González, 1993, 1997).

Foram empregadas apenas as informações sobre apartamentos residenciais, desde os compactos (conhecidos em Porto Alegre como "JK") até os de três dormitórios, de janeiro de 1991 a abril de 1997, conforme pode ser verificado nas Figuras 1 e 2, a seguir. Os valores dos aluguéis foram corrigidos monetariamente através do IGP-DI, atualizando-se os preços até maio de 1997. A escolha dos apartamentos para representar a locação residencial justifica-se por serem tipicamente $94 \%$ das unidades ofertadas, restando apenas $6 \%$ para as casas. Os imóveis de quatro ou mais dormitórios foram desconsiderados, pela pequena representatividade. Os dados estão listados no Anexo Estatístico (Tabela A1).

Figura 1 - Variação da oferta de apartamentos em Porto Alegre (unidades)

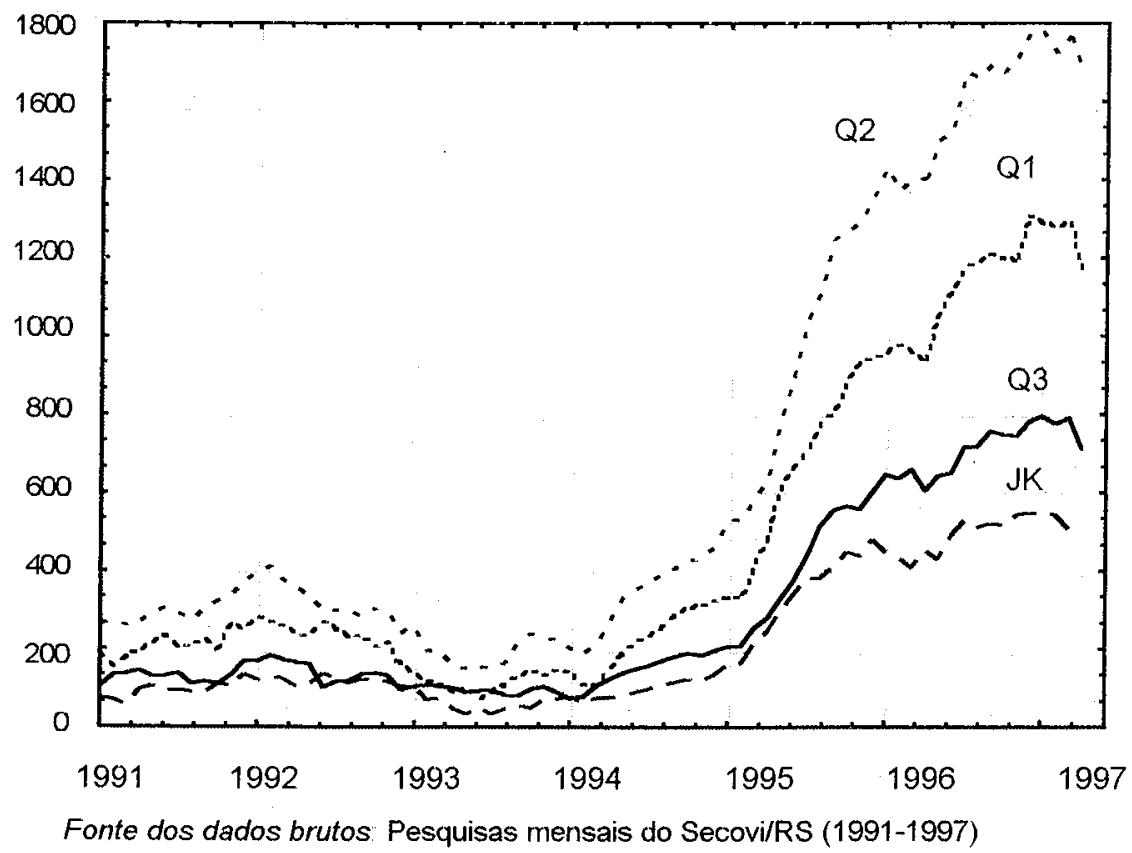


A primeira ilustração apresenta a variação da oferta de apartamentos, por tipo (Figura 1). Pode-se verificar que os niveis de oferta na época do Plano Real eram semelhantes aos praticados no ano de 1991 . É interessante identificar alguns pontos, para referenciar melhor o gráfico. Em janeiro de 1991, a oferta de apartamentos residenciais era de 631 unidades. Em junho de 1994, era de 801 unidades, atingindo 4438 apartamentos em Dezembro de 1996. Em 1997, ocorreu uma pequena redução nas ofertas, chegando a 4061 apartamentos em abril. A oferta mensal média em 1991 foi de 730 unidades/mês, enquanto que, em 1996, foi de mais de 3800 unidades/mês. Assim, no período de janeiro de 1991 a junho de 1994, a oferta cresceu apenas $27 \%$, enquanto que no período após a edição do Plano Real o crescimento foi de $400 \%$.

Analisando a Figura 1, percebe-se um crescimento na disponibilidade de apartamentos para aluguel, ocorrido desde o Plano Real, lento nos primeiros meses, mas acentuando-se em 1995 e 1996. Como não ocorreu nenhum boom imobiliário na cidade, mantendo-se niveis razoáveis de construção de imóveis novos, trata-se da entrada no mercado de imóveis que estavam sem utilização, servindo como reservas monetárias ou garantias de longo prazo. Porto Alegre têm cerca de 450 mil imóveis registrados no cadastro municipal, sendo que mais de $200 \mathrm{mil}$ são apartamentos. Aceitando-se a hipótese de que os dados apresentados são $80 \%$ da oferta real, esta representaria $2.5 \%$ do estoque, em fins de 1996.

A Figura 2 mostra variações de preços que parecem não acompanhar as variações de oferta. Mesmo com o crescimento da oferta, os preços aumentaram até meados de 1995 , atingindo os níveis do início da década, só então iniciando o declínio observado atualmente. Ou seja, a estabilidade do primeiro ano do Plano Real e o aumento da oferta não foram suficientes para baixar os preços, ou ao menos mantê-los nos níveis de julho de 1994. A Tabela 1, na seqüência, apresenta alguns dos dados sobre preços, pontuando o gráfico, para esclarecer mais a análise. Os dados (Figura 2 e Tabela 1) revelam um aumento de preços no ano seguinte ao Plano Real. Os preços de junho de 1994 e junho de 1996 são praticamente iguais. A diminuição que ocorreu em seguida à edição do Plano (de junho para julho de 1994) foi compensada com valores crescentes, atingindo o mesmo patamar um ano após. Só então os valores começaram a decair novamente. Atualmente, estão cerca de $5 \%$ abaixo dos níveis de julho de 1994. Ou seja, os dados demonstram que os aluguéis estão diminuindo, mas que apenas recentemente a estabilização econômica provocou queda nos preços (Secovi, 1991-1997). 
Figura 2 - Preços médios mensais dos aluguéis de apartamentos em Porto Alegre (R\$)

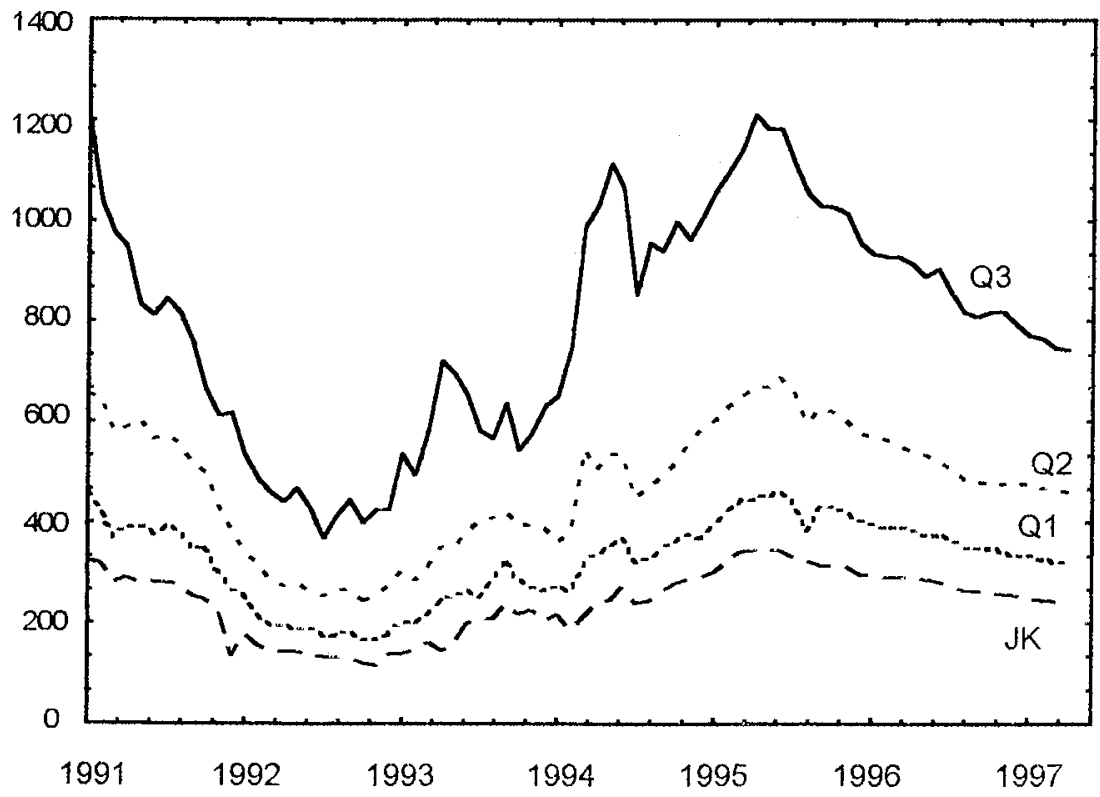

Obs.: Valores corrigidos por IGP-DI para maio de 1997

Fonte dos dados brutos: Pesquisas mensais do Secovi/RS (1991-1997);

Tabela 1 - Preços médios dos aluguéis em Porto Alegre, por tipo de apartamento e ponderado pelas respectivas ofertas (R\$)

\begin{tabular}{l|c|c|c|c|c}
\hline Mês-ano & JK & Q1 & Q2 & \multicolumn{1}{c|}{ Q3 } & $\begin{array}{c}\text { Média } \\
\text { ponderada }\end{array}$ \\
\hline Janeiro-1991 & 324.90 & 460.00 & 655.75 & 1211.45 & 649.66 \\
Junho-1994 & 272.83 & 366.65 & 536.52 & 1065.41 & 560.21 \\
Julho-1994 & 239.37 & 323.21 & 449.76 & 853.78 & 465.53 \\
Junho-1995 & 345.59 & 461.71 & 690.65 & 1183.82 & 653.58 \\
Junho-1996 & 282.79 & 374.37 & 525.50 & 904.88 & 514.72 \\
Dezemb. -1996 & 255.11 & 333.03 & 475.28 & 794.16 & 462.45 \\
Abril-1997 & 242.27 & 320.25 & 459.95 & 743.79 & 443.41 \\
\hline
\end{tabular}

Obs: Valores corrigidos por IGP-DI para maio de 1997

Fonte dos dados brutos: Pesquisas mensais do Secovi/RS (1991-1997)

A oferta só aumentou após a garantia de um cenário otimista para os proprietários. Porém, o brutal aumento de oferta de imóveis não teve uma 
influência muito significativa nos preços. Um crescimento da oferta para quantia cinco vezes maior que a da época do Plano Real deveria refletir-se em maiores quedas de preços. A diminuição de preços foi apenas de $21 \%$ entre junho de 1994 e abril de 1997 e de $32 \%$ entre janeiro de 1991 e abril de 1997. Considerando que há um processo de estabilização e uma legislação bem mais favorável ao proprietário do que a anterior e, mais importante, que os valores recebidos no período entre os reajustes (tipicamente semestral) são praticamente constantes, esperava-se realmente uma queda maior. Os aluguéis recebidos durante o ano são maiores, atualmente, por causa da inflação reduzida. Apenas estas causas já justificariam uma diminuição de preços. Pode-se até dizer que o aumento de oferta, em si, não teve influência nos preços, inicialmente.

\section{MODELOS HEDÔNICOS DE PREÇOS DE ALUGUÉIS}

A análise realizada com dados destas pesquisas mensais é interessante para identificar as tendências gerais. Contudo, as características especiais do mercado fazem com que os imóveis sejam bens compostos, que não podem ser comparados diretamente. Na literatura, existem exemplos de diversas tentativas de criação de índices de preços genéricos, e das dificuldades que sobrevem destas análises. A única forma prática de comparação de valores é através de modelos hedônicos, usando-se a regressão múltipla para ponderar os diversos atributos, de acordo com as evidências do mercado, investigadas por uma amostra representativa (González, 1993; Marks, 1984; Olsen, 1972; Palmquist, 1980; Rosen, 1974).

Desta forma, é preciso obter as evidências diretamente em amostragens do mercado de locações, na forma tradicional. Trata-se de uma amostragem mista, simultaneamente time series e cross-section. É importante distribuir a amostra por toda a região de oferta, evitando efeitos localizados, que poderiam refletir a situação momentânea de um bairro apenas, por exemplo. Por outro lado, o período coberto deve ser razoavelmente amplo. A investigação dos efeitos deste plano sobre os aluguéis ofertados no mercado imobiliário em Porto Alegre foi realizada através de modelos de preços hedônicos, medindo as variações nos aluguéis de apartamentos residenciais no período entre janeiro de 1993 e dezembro de 1996.

\subsection{Amostra obtida e variáveis}

Foram coletadas informações sobre valores de aluguéis, buscando-se cobrir os tipos comuns de imóveis ofertados, excluindo-se os especiais, que 
fogem às regras comuns do mercado. Assim, os apartamentos de cobertura, os mobiliados, os de alto luxo e os de locação sob regras comerciais não foram considerados. Os dados foram obtidos junto às imobiliárias locais, consistindo de 980 apartamentos residenciais, distribuídos pelos diversos bairros da cidade. As variáveis consideradas permitem a identificação das distinções entre os imóveis, que justificam as variações de preços. Estas medidas são as descritas a seguir.

A variável dependente é o valor ofertado dos aluguéis (aluguel). Os valores (em reais) foram corrigidos pelo IGP-DI (da Fundação Getúlio Vargas), para maio de 1997. Das independentes, a área total (área) e a idade fiscal (idade) foram obtidas em consultas ao cadastro da Prefeitura Municipal de Porto Alegre. Bairro é uma variável qualitativa, que classifica os bairros da cidade, variando de 1, no pior, até 25 , no melhor. Mês indica o número de meses decorridos desde o início do período, janeiro de 1993, até a data de referência do imóvel, variando de 1 (jan.93) a 48 (dez.96), portanto. O conjunto de dummies Q1/Q2/Q3 indica o número de dormitórios do apartamento. Quando são simultaneamente iguais a zero, trata-se de um JK. O tempo foi melhor considerado através de um conjunto de dummies mensais, correspondendo aos trimestres no período, variando de $M 1$ (jan.93) a M48 (dez.96). Depemp indica se o imóvel possui dependências de empregada. Garagem é uma variável binária que indica a existência de espaço para estacionamento. Luxo identifica imóveis de padrão superior aos demais. Por fim, distância é uma medida, em linha reta e em $\mathrm{km}$, do imóvel até um ponto de referência no centro da cidade (a Prefeitura Municipal), representando a distância ao $C B D$.

A amostra considerou apartamentos do tipo JK, de um, dois e três dormitórios. As características da amostra podem ser identificadas na Tabela 2, que apresenta as médias para algumas das variáveis coletadas, por tipo de imóvel. Os valores dos aluguéis são apresentados com a correção monetária pelo IGP-DI, até maio de 1997.

Tabela 2 - Caracteristicas médias da amostra

\begin{tabular}{l|r|r|r|r|r}
\hline variável & \multicolumn{1}{|c|}{$\mathrm{JK}$} & \multicolumn{1}{|c|}{$\mathrm{Q} 1$} & \multicolumn{1}{c}{ Q2 } & \multicolumn{1}{c}{ Q3 } & \multicolumn{1}{c}{ Geral } \\
\hline Aluguel (R\$) & 261.75 & 368.40 & 514.40 & 719.76 & 449.21 \\
Área $\left(\mathrm{m}^{2}\right)$ & 32.25 & 51.94 & 70.71 & 92.19 & 60.66 \\
Bairro & 5.42 & 5.93 & 5.92 & 7.26 & 5.98 \\
Distáncia (km) & 1.31 & 5.43 & 5.46 & 4.52 & 4.56 \\
ldade (anos) & 25.13 & 18.27 & 19.54 & 24.17 & 20.75 \\
Mês & 22.17 & 27.72 & 27.84 & 27.19 & 26.66 \\
número & 185 & 268 & 420 & 107 & 980 \\
(\%) & 18.88 & 27.35 & 42.86 & 10.92 & 100.00 \\
\hline
\end{tabular}




\subsection{Ajustamento de modelos hedônicos}

A forma real de relacionamento das variáveis não é conhecida. A análise inferencial permite a investigação e teste de hipóteses. $O$ modelo inicial é o linear, convencional em formato, conforme indicado a seguir em (1). Com base neste modelo simples foram feitos testes de especificações alternativas. No modelo apresentado a seguir, as variáveis são as descritas acima, e os coeficientes $a_{i}$ são os termos a serem estimados por regressão. As variáveis são aceitas se atingirem a significância mínima de 90\%, durante a rotina stepwise.

Modelo linear básico;

$$
\begin{aligned}
\text { Aluguel }= & a_{0}+a_{1}{ }^{\star} \text { Área }+a_{2}{ }^{\star} \text { Bairro }+a_{3}{ }^{\star} \text { Depemp }+a_{4}{ }^{\star} \text { Distância } \\
& +a_{5}{ }^{\star} \text { Garagem }+a_{6}{ }^{\star} \text { Idade }+a_{7}{ }^{\star} \text { Luxo }+a_{8}{ }^{\star} Q 1+a_{9}{ }^{*} Q 2+a_{10}{ }^{\star} Q 3 \\
& +a_{11}{ }^{\star} M 1+\ldots+a_{58}{ }^{\star} M 48
\end{aligned}
$$

Foram testadas várias formas para a variável dependente (valor do aluguel), verificando-se modelos com o valor total linear e com transformações por raiz quadrada e logaritmos naturais. $O$ melhor desempenho deu-se com Ln(A/ugue/), optando-se por esta variável para a continuação da análise. Os testes estatísticos foram semelhantes, permitindo optar-se livremente entre os modelos, escolhendo-se o de melhor desempenho. Assim, o modelo escolhido foi o semi-logarítmico.

O uso de variáveis singulares para medição das variações reais não foi produtivo. Inicialmente, empregou-se uma única variável (mês) e, em seguida, três variáveis: uma para o período antes do Plano Real, outra para o período entre julho de 1994 e junho de 1995, e outra para o restante. Porém as variações de preços são mais complexas, como já indicavam os dados apresentados acima (Figuras 1 e 2). Buscando melhorar o entendimento da questão e o ajustamento do modelo, estas variáveis simples foram substituídas por um conjunto de dummies mensais. As variáveis, nomeadas como $M 1 \ldots M 48$, assumem valor um ou zero, conforme a posição do imóvel no tempo, contando-se os meses seqüencialmente a partir de janeiro de 1993. Foram incluídas todas as variáveis, removendo em cada passagem a de menor $t$ (uma por vez), até que todas estivessem no limite determinado. $O$ conjunto final obtido foi $o$ apresentado na Tabela 3.

- modelo apresentado tem parâmetros estatísticos significativos: $85,88 \%$ de coeficiente de determinação e 133,27 no teste $F$. As variáveis passaram todas no teste $t$, com significância maior que $90 \%$. Os testes dos pressupostos básicos, tais como normalidade, heterocedasticidade, 
comportamento dos residuos, colinearidade, foram adequados. Como aceita-se que a amostra é de boa qualidade e pode representar o universo, o modelo pode ser empregado para analisar o mercado, portanto.

Tabela 3 - Modelo hedônico de preços de aluguel para Porto Alegre, ajustado com dummies mensais [variável dependente: Ln(Aluguel)]

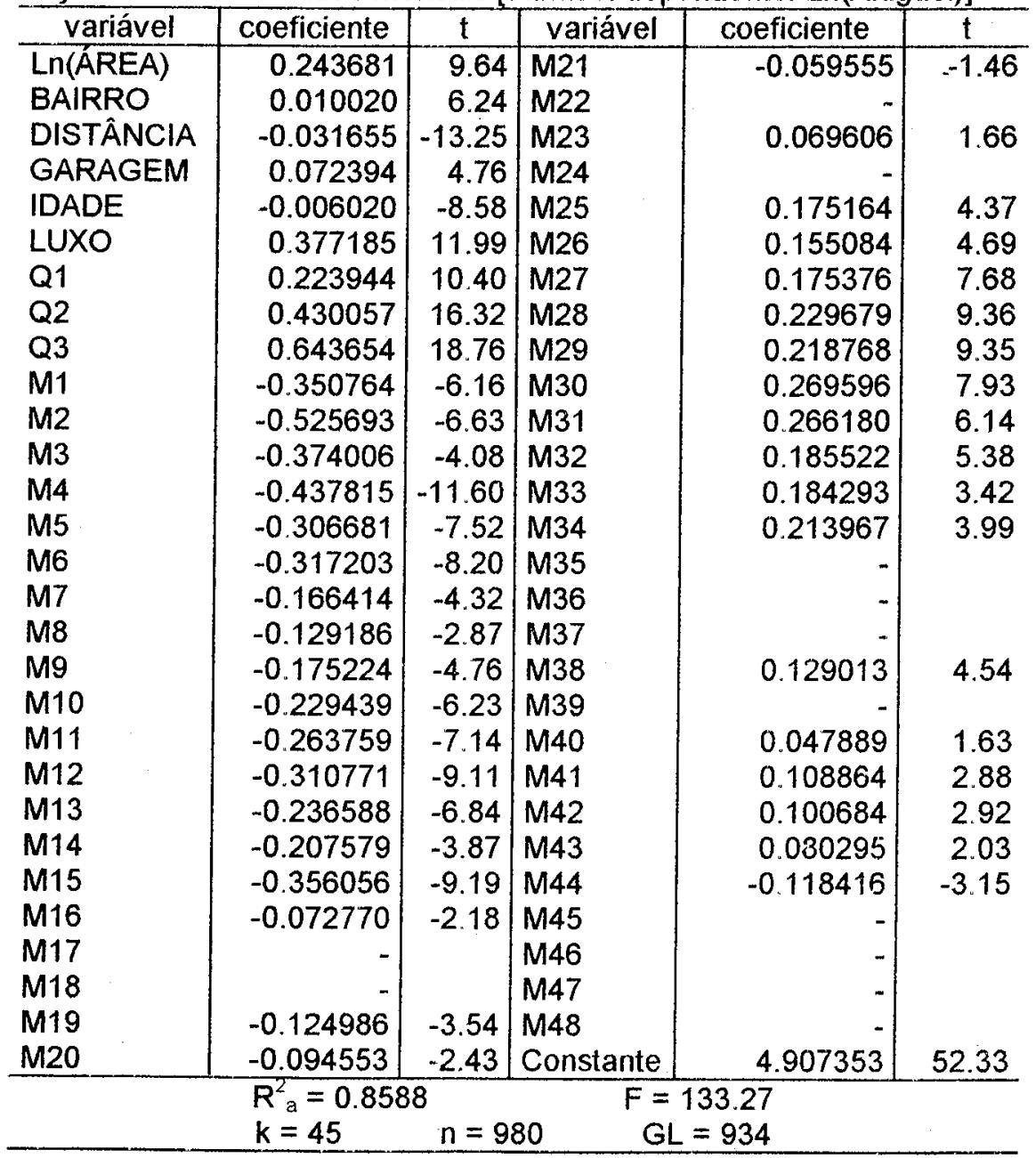

A principal verificação a ser realizada é quanto às variações de preços. 
A utilização de dummies permite construir uma curva com muitas oscilações, o que não seria possível com variações simples. A Figura 3 apresenta as curvas de preços, estimadas com as médias para cada tipo de imóvel (ver Tabela 2). Os intervalos deste gráfico foram mantidos iguais aos da Figura 2, para facilitar a comparação. Os valores calculados estão no Anexo Estatístico (Tabela A2).

Os gráficos das Figuras 2 e 3 são bastante semelhantes, com formatos coincidentes em grande parte da série. As diferenças em relação à pesquisa do Secovi podem ser decorrentes de diferenças nos imóveis considerados (não foram incluídos imóveis de alto luxo, por exemplo) e de eventuais participações distintas para cada bairro ou tipo de imóvel.

Figura 3 - Curvas de preços dos aluguéis por tipo de apartamento em Porto Alegre

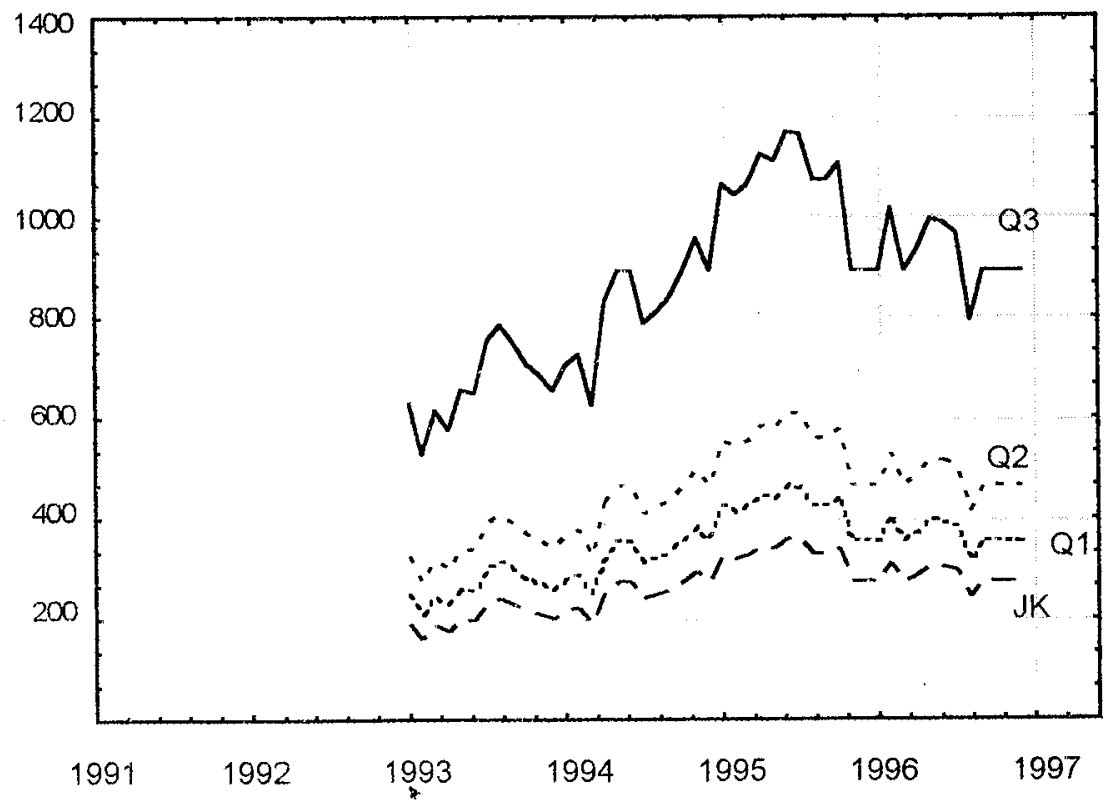

Obs: Valores estimados pela equação da Tabela 3 e corrigidos pelo IGP-DI para maio de 1997

Fonte: Dados coletados e modelos ajustados pelo autor.

A pesquisa mensal do Secovi coleta todos os imóveis ofertados, o que não pode ser realizado na análise de modelos hedônicos por causa do 
maior detalhamento necessário. Por outro lado, a semelhança de resultados permite a escolha do método, com a garantia de que os resultados serão semelhantes: a coleta exaustiva de dados com análise estatística simples ou a amostragem detalhada, ajustando-se modelos de formação de preços. Cada qual tem suas vantagens, embora a análise de regressão tenha vantagens na previsão de valore:s.

\section{CONCLUSÃO}

O mercado imobiliário tem grande importância dentro da economia, sendo influenciado por inúmeros fatores, públicos e privados. $A$ condução econômica do Governo Federal tem influências sobre o mercado, pelas medidas macroeconômicas e pela intervenção e regulamentação das relações entre proprietários e inquilinos. A análise da situação recente foi realizada através de dados genéricos, coletados pelo sindicato das imobiliárias, e com modelos hedônicos de preços, como em trabalhos anteriores (González, 1993/1995/1997; Secovi, 1991-1997).

O exame da pesquisa do Secovi/RS demonstra um forte crescimento da oferta, desde 1995 (Figura 1). Contudo, não se refletiu em diminuição dos preços. Os preços médios dos aluguéis foram utilizados para identificar o formato geral da curva de preços no periodo analisado (Figura 2). Resumidamente, percebe-se que os preços praticados no inicio de 1997 são semelhantes aos da época da edição do Plano Real.

Complementando, as variações provocadas pelo Real foram medidas através de uma amostra de 980 apartamentos, representando o mercado de locações residenciais em Porto Alegre, em um período de 48 meses. Esta investigação foi feita por modelos de regressão múltipla, com formas alternativas de medição da variação real nos preços.

O bom desempenho estatístico dos modelos hedônicos e o conjunto de dados utilizados permitem que se busquem algumas previsões. $O$ grande crescimento do número de imóveis ofertados que ocorreu em 1995-1997 (Figura 1) não deve prosseguir. Provavelmente o gradiente diminuirá, como indicam os primeiros meses de 1997, com a oferta tendendo à estabilização em um patamar de 4000 apartamentos, no final de 1997.

O modelo hedônico utilizado indicou a diminuição progressiva nos aluguéis, no período mais recente, de junho de 1995 em diante, já descontada a inflação, que foi medida pelo IGP-DI. Tendo em vista o crescimento anterior dos aluguéis, em abril de 1997 o mercado apenas logrou atingir os níveis da época da implantação do Plano Real. Como as variáveis binárias referentes aos últimos meses analisados não foram significantes (M45 ... M48), pode-se supor que os preços estão se estabilizando. 


\section{ANEXO ESTATÍSTICO}

Tabela A1 - Dados da Pesquisa Mensal do Secovi

- Oferta de apartamentos e Preços médios (corrigidos para maio de 1997 por IGP-DI) em Porto Alegre, 1991 - 1997

\begin{tabular}{|c|c|c|c|c|c|c|c|c|c|c|c|}
\hline \multirow{2}{*}{$\begin{array}{l}\mathrm{N} \text { de } \\
\text { Obs. }\end{array}$} & \multirow[b]{2}{*}{ Mês } & \multirow[b]{2}{*}{ Ano } & \multicolumn{5}{|c|}{ OFERTA } & \multicolumn{4}{|c|}{ PRECO MÉDIO } \\
\hline & & & $J K$ & Q1 & Q2 & Q3 & Total* & PMJK & PMQ1 & PMQ2 & PMQ3 \\
\hline 1 & 1 & 91 & 75 & 188 & 261 & 104 & $\widetilde{631}$ & 32490 & 460.00 & 65575 & $\overline{1211.45}$ \\
\hline 2 & 2 & 91 & 70 & 156 & 273 & 133 & 635 & 31954 & 42364 & 64858 & 103753 \\
\hline 3 & 3 & 91 & 57 & 179 & 260 & 136 & 635 & 280.96 & 372.45 & 579.59 & 97695 \\
\hline 4 & 4 & 91 & 96 & 188 & 268 & 144 & 697 & 291.93 & 38851 & 58854 & 951.05 \\
\hline 5 & 5 & 91 & 107 & 211 & 292 & 129 & 743 & 28188 & 391.53 & 605.06 & 83503 \\
\hline 6 & 6 & 91 & 94 & 229 & 306 & 132 & 766 & 28345 & 37519 & 566.86 & 81267 \\
\hline 7 & 7 & 91 & 95 & 205 & 291 & 138 & 733 & 28085 & 392.92 & 57373 & 846.19 \\
\hline 8 & 8 & 91 & 88 & 204 & 274 & 110 & 681 & 27646 & 380.25 & 555.60 & 817.88 \\
\hline 9 & 9 & $9 i$ & 87 & 225 & 301 & 117 & 737 & 25534 & 342.97 & 518.66 & 75970 \\
\hline 10 & 10 & 91 & 110 & 196 & 322 & 110 & 742 & 247.08 & 35283 & 49784 & 663.23 \\
\hline 11 & 11 & 91 & 105 & 262 & 339 & 133 & 843 & 22349 & 302.41 & 43108 & 61193 \\
\hline 12 & 12 & 91 & 135 & 255 & 371 & 167 & 928 & 134.20 & 26524 & 38355 & 61740 \\
\hline 13 & 1 & 92 & 121 & 277 & 397 & 168 & 968 & 178.84 & 24951 & 340.13 & 533.32 \\
\hline 14 & 2 & 92 & 129 & 273 & 413 & 184 & 1003 & 156.10 & 21524 & 318.34 & 487.41 \\
\hline 15 & 3 & 92 & 122 & 260 & 374 & 172 & 933 & 147.23 & 197.29 & 284.75 & 45992 \\
\hline 16 & 4 & 92 & 103 & 229 & 360 & 166 & 862 & 14369 & 193.36 & 27536 & 441.94 \\
\hline 17 & 5 & 92 & 109 & 234 & 332 & 162 & 842 & 14424 & 19159 & 280.24 & 468.96 \\
\hline 18 & 6 & 92 & 138 & 266 & 302 & 102 & 810 & 137.72 & 18659 & 26406 & 42954 \\
\hline 19 & 7 & 92 & 124 & 247 & 298 & 117 & 790 & 13352 & 17311 & 255.86 & 368.80 \\
\hline 20 & 8 & 92 & 112 & 230 & 297 & 120 & 764 & 131.35 & 17735 & 26487 & 412.49 \\
\hline 21 & 9 & 92 & 124 & 229 & 283 & 136 & 776 & 130.21 & 181.54 & 26791 & 44589 \\
\hline 22 & 10 & 92 & 119 & 204 & 303 & 138 & 773 & 120.76 & 164.49 & 245.47 & 401.32 \\
\hline 23 & 11 & 92 & 116 & 218 & 293 & 132 & 760 & 11586 & 16786 & 25409 & 426.05 \\
\hline 24 & 12 & 92 & 103 & 165 & 240 & 95 & 605 & 13859 & 17781 & 27488 & 426.34 \\
\hline 25 & 1 & 93 & 106 & 137 & 261 & 104 & 614 & 139.06 & 203.21 & 30500 & 536.17 \\
\hline 26 & 2 & 93 & 70 & 115 & 196 & 108 & 497 & 147.10 & 204.84 & 286.08 & 495.78 \\
\hline 27 & 3 & 93 & 75 & 110 & 193 & 104 & 487 & 161.55 & 21923 & 31505 & 582.74 \\
\hline 28 & 4 & 93 & 47 & 90 & 154 & 100 & 394 & 145.38 & 24555 & 353.35 & 720.91 \\
\hline 29 & 5 & 93 & 34 & 101 & 151 & 89 & 379 & 159.05 & 25205 & 351.75 & $\$ 97.20$ \\
\hline 30 & 6 & 93 & 51 & $\infty$ & 152 & 94 & 369 & 199.45 & 266.39 & 38020 & 653.70 \\
\hline 31 & 7 & 93 & 33 & 88 & 154 & 94 & 372 & 20853 & 249.56 & 403.26 & 582.49 \\
\hline 32 & 8 & 93 & 47 & 105 & 164 & 82 & 404 & 210.64 & 286.28 & 41091 & 567.26 \\
\hline 33 & 9 & 93 & 55 & 132 & 219 & 80 & 492 & 237.22 & 324.32 & 421.82 & 637.95 \\
\hline 34 & 10 & 93 & 48 & 143 & 240 & 98 & 537 & 217.68 & 28762 & 395.18 & 544.54 \\
\hline 35 & 11 & 93 & 70 & 135 & 229 & 103 & 545 & 227.39 & 27436 & 397.60 & 578.23 \\
\hline 36 & 12 & 93 & 71 & 144 & 226 & 89 & 537 & 206.48 & 267.47 & 389.51 & 632.46 \\
\hline 37 & 1 & 94 & 79 & 144 & 201 & 72 & 499 & 219.17 & 269.74 & 36321 & 651.75 \\
\hline 38 & 2 & 94 & 62 & 108 & 186 & 79 & 441 & 188.04 & 26701 & 38178 & 748.77 \\
\hline 39 & 3 & 94 & 74 & 109 & 214 & 107 & 508 & 215.88 & 321.02 & 54568 & 989.73 \\
\hline 40 & 4 & 94 & 77 & 148 & 273 & 123 & 625 & 23965 & 33955 & 50697 & 1029.17 \\
\hline 41 & 5 & 94 & 80 & 187 & 332 & 138 & 741 & 247.16 & 345.81 & 537.93 & 1113.59 \\
\hline
\end{tabular}


Tabela A1 - Dados da Pesquisa Mensal do Secovi

- Oferta de apartamentos e Preços médios (corrigidos para maio de 1997 por (GP-DI) em Porto Alegre, 1991 - 1997

\begin{tabular}{|c|c|c|c|c|c|c|c|c|c|c|c|}
\hline \multirow{2}{*}{$\begin{array}{l}N \text { de } \\
\text { Obs. }\end{array}$} & \multirow[b]{2}{*}{ Mês } & \multirow[b]{2}{*}{ Ano } & \multicolumn{5}{|c|}{ OFERTA } & \multicolumn{4}{|c|}{ PRECCO MÉDIO } \\
\hline & & & $\mathrm{JK}$ & Q1 & Q2 & Q3 & Total ${ }^{\star}$ & PMJK & PMQ1 & PMQ2 & PMQ3 \\
\hline 42 & 6 & 94 & 89 & 211 & 350 & 148 & 801 & 272.83 & 366.65 & 536.52 & 1065.41 \\
\hline 43 & 7 & 94 & 97 & 236 & 369 & 158 & 863 & 239.37 & 323.21 & 449.76 & 853.78 \\
\hline 44 & 8 & 94 & 106 & 260 & 388 & 169 & 925 & 24430 & 326.69 & 471.24 & 956.94 \\
\hline 45 & 9 & 94 & 114 & 285 & 407 & 180 & 988 & 262.50 & 348.56 & 492.10 & 939.48 \\
\hline 46 & 10 & 94 & 123 & 309 & 426 & 190 & 1049 & 278.91 & 36205 & 519.34 & 998.30 \\
\hline 47 & 11 & 94 & 119 & 314 & 431 & 183 & 1048 & 287.45 & 377.68 & 560.32 & 963.75 \\
\hline 48 & 12 & 94 & 133 & 323 & 462 & 195 & 1114 & 293.63 & 37228 & 586.94 & 1007.40 \\
\hline 49 & 1 & 95 & 162 & 330 & 529 & 206 & 1229 & 303.29 & 397.11 & 603.66 & 1060.49 \\
\hline 50 & 2 & 95 & 162 & 330 & 529 & 206 & 1229 & 325.72 & 427.73 & 631.04 & 1098.27 \\
\hline 51 & 3 & 95 & 215 & 425 & 584 & 256 & 1486 & 342.51 & 446.86 & 650.19 & 1140.22 \\
\hline 52 & 4 & 95 & 246 & 486 & 633 & 280 & 1650 & 346.53 & 447.28 & 669.29 & 1211.08 \\
\hline 53 & 5 & 95 & 301 & 615 & 793 & 331 & 2048 & 347.75 & 455.05 & 670.36 & 1184.10 \\
\hline 54 & 6 & 95 & 340 & 670 & 900 & 377 & 2295 & 345.59 & 46171 & 690.65 & 118382 \\
\hline 55 & 7 & 95 & 380 & 709 & 1044 & 440 & 2588 & 332.62 & 448.53 & 661.68 & 111564 \\
\hline 56 & 8 & 95 & 380 & 775 & 1110 & 515 & 2791 & 324.95 & 385.09 & 598.25 & 1058.05 \\
\hline 57 & 9 & 95 & 410 & 810 & 1248 & 555 & 3034 & 315.60 & 432.12 & 626.55 & 1031.87 \\
\hline 58 & 10 & 95 & 448 & 895 & 1271 & 565 & 3193 & 31498 & 428.74 & 620.64 & 102728 \\
\hline 59 & 11 & 95 & 438 & 929 & 1290 & 558 & 3227 & 313.73 & 417.08 & 604.05 & 1015.08 \\
\hline 60 & 12 & 95 & 480 & 943 & 1354 & 601 & 3392 & 298.57 & 401.53 & 579.73 & 958.03 \\
\hline 61 & 1 & 96 & 449 & 957 & 1433 & 647 & 3503 & 296.21 & 39746 & 570.04 & 934.62 \\
\hline 62 & 2 & 96 & 434 & 974 & 1373 & 635 & 3439 & 29191 & 390.67 & 566.44 & 930.14 \\
\hline$\varpi$ & 3 & 96 & 409 & 958 & 1399 & 659 & 3445 & 290.71 & 387.55 & 554.54 & 928.73 \\
\hline 64 & 4 & 96 & 452 & 933 & 1403 & 607 & 3405 & 293.28 & 38364 & 54298 & 916.10 \\
\hline 65 & 5 & 96 & 429 & 1050 & 1500 & 642 & 3634 & 287.66 & 377.48 & 536.77 & 891.04 \\
\hline 66 & 6 & 96 & 492 & 1111 & 1523 & 650 & 3789 & 28279 & 374.37 & 525.50 & 904.88 \\
\hline 67 & 7 & 96 & 529 & 1170 & 1676 & 716 & 4114 & 274.41 & 370.17 & 50937 & 857.48 \\
\hline 68 & 8 & 96 & 511 & 1191 & 1661 & 720 & 4101 & 265.61 & 351.86 & 488.86 & 818.76 \\
\hline 69 & 9 & 96 & 522 & 1213 & 1696 & 758 & 4209 & 262.62 & 349.73 & 482.41 & 808.78 \\
\hline 70 & 10 & 96 & 516 & 1198 & 1675 & 749 & 4158 & 260.78 & 345.16 & 478.17 & 819.44 \\
\hline 71 & 11 & 96 & 542 & 1189 & 1715 & 744 & 4202 & 258.03 & 342.33 & 476.33 & 819.48 \\
\hline 72 & 12 & 96 & 549 & 1304 & 1783 & 783 & 4438 & 255.11 & 333.03 & 475.28 & 79416 \\
\hline 73 & 1 & 97 & 545 & 1288 & 1778 & 795 & 4418 & 249.94 & 331.33 & 478.60 & 772.72 \\
\hline 74 & 2 & 97 & 545 & 1279 & 1726 & 776 & 4348 & 24633 & 325.41 & 468.61 & 766.09 \\
\hline 75 & 3 & 97 & 508 & 1287 & 1768 & 792 & 4374 & 243.92 & 323.27 & 466.57 & 748.92 \\
\hline 76 & 4 & 97 & 492 & 1160 & 1671 & 713 & 4061 & 242.27 & 320.25 & 459.95 & 743.79 \\
\hline
\end{tabular}

Obs.: "Total dos tipos considerados Não inclui os apartamentos de quatro dormitórios e outros tipos de imóveis

Fonte dos dados brutos: Pesquisas mensais do Secovi/RS (1991-1997) 
Tabela A2 - Preços estimados pela equação da Tabela 3

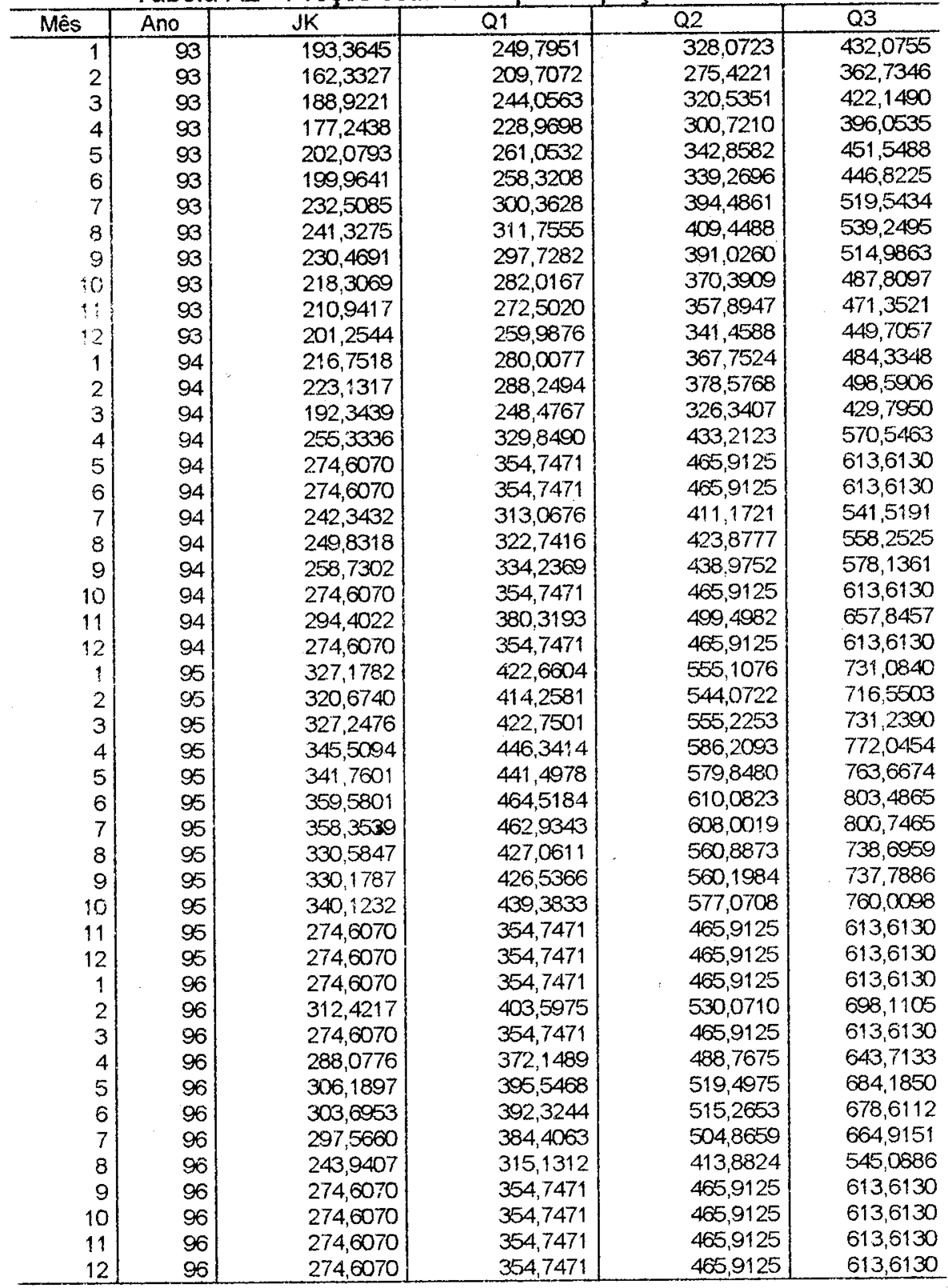




\section{BIBLIOGRAFIA}

GONZÁLEZ, Marco Aurélio Stumpf. A formação do valor de aluguéis de apartamentos residenciais na cidade de Porto Alegre Porto Alegre: UFRGS, 1993 Dissertação (Mestrado em Engenharia).

O comportamento dos aluguéis residenciais no plano real - estudo do caso de Porto Alegre (1993-95). Anais - VIII COBREAP (Congresso Brasileiro de Engenharia de Avaliações e Pericias). Florianópolis ICAPE/ABRAP, p.363-367, Nov 1995.

Estimación de modelos de precios hedónicos para alquileres residenciales. Cuadernos de Economia, a 34, n.101, Abr. 1997

KEMPNER, Jonathan L e FINE, Michael. The high cost of rent control The Real State Finance Journal, p. 57-62, Summer, 1989

LAVENDER, S. D. Economics for builders and surveyors. Essex. Longman, 1990.

MARKS, Denton. The effects of rent control on the price of rental housing an hedonic approach. Land Economics, v 60, n.1, p.81-94, Feb 1984.

OLSEN, Edgar O. An econometric analysis of rent control Journal of Political Economy, v 80, n. 6 , p. 1081-1100, Dec 1972

PALMQUIST, Raymond B. Alternative techniques for developing real estate price indexes. The Review of Economics and Statistics, v.62, n.3, p.442-448, Aug. 1980

ROBINSON, Ray. Housing economics and public policy. London: McMillan, 1979

ROSEN, Sherwin. Hedonic prices and implicit markets: product differenciation in pure competition. Jornal of Political Economy, v.82, p.34-55, Jan 1974

- SECOVI (Sindicato das Empresas de Compra, Venda, Locação e Administração de Imóveis Residenciais e Comerciais do Estado do Rio Grande do Sul). Pesquisa do mercado imobiliário em Porto Alegre. Porto Alegre. SECOVI, 1991-1996 (mensais).

WIKTORIN, Marianne. An international comparison of rent setting and conflict resolution Gävle (Sweden): Swedish Institute for Building Research, 1992 